\section{THE NORWOOD OPERATION AND SUBSEQUENT FONTAN OPERATION IN INFANTS WITH COMPLEX CONGENITAL HEART DISEASE}

From April 1987 to September 1993, 60 infants underwent a Norwood operation for complex congenital heart disease including hypoplastic left heart syndrome $(n=$ 41), ventricular septal defect and subaortic stenosis with aortic arch interruption/ severe coarctation $(n=7)$, complex single right ventricle with subaortic stenosis $(n=8)$, critical aortic stenosis with endocardial fibroelastosis $(n=2)$, and malaligned primum atrial septal defect with coarctation $(n=2)$. Age at operation ranged from 1 day to 3.9 months (mean 9 days, median 3.5 days). The operative mortality (<30 days) was $33 \%$ (20 patients). Late mortality was $17 \%$ (10 patients). Nine of the $20(45 \%)$ operative deaths occurred during the first 2 days after the operation as a result of sudden hemodynamic instability. All four infants with premature closure of the foramen ovale had pulmonary lymphangiectasia and died of pulmonary failure. Seven operative deaths have occurred in 36 patients since 1990 $(19 \%)$; in the past 2 years, no operative deaths have occurred in 22 patients. Overall, there are 30 long-term survivors $(50 \%)$. Twenty-one of these 30 infants have undergone a two-stage repair with a modified Fontan operation at 7.3 to 27.6 months of age (mean 18.1 months) with no mortality. Six patients have entered a three-stage repair strategy by undergoing a hemi-Fontan procedure at 6.8 to 23.0 months (mean 8.8 months) with no mortality, and two of these patients have now had their modified Fontan operation at 23.0 to 46.7 months of age with no mortality (four are still awaiting surgery). Two patients have undergone a two-ventricle repair with a Rastelli procedure, with no mortality at 7.4 and 14.1 months of age. Early in our experience, infants undergoing the Norwood operation had a high early mortality most often related to sudden hemodynamic instability. After we instituted a protocol that adds carbon dioxide to the inspired gas during postoperative mechanical ventilation, the postoperative course became more stable and there have been no operative deaths. In summary, the operative mortality for the Norwood operation continues to improve. A subsequent Fontan operation can be performed with excellent clinical results. (J THORAC CARDIOVASC SURG 1995;109:654-62)

Paul W. Weldner, MD ${ }^{\mathrm{a}}$ (by invitation), John L. Myers, MD, ${ }^{\mathrm{a}}$ Marie M. Gleason, MD (by invitation), Stephen E. Cyran, $\mathrm{MD}^{\mathrm{b}}$ (by invitation), Howard S. Weber, $\mathrm{MD}^{\mathrm{b}}$ (by invitation), Michael G. White, $\mathrm{MD}^{\mathrm{b}}$ (by invitation), and Barry G. Baylen, $\mathrm{MD}^{\mathrm{b}}$ (by invitation), Hershey, $\mathrm{Pa}$.
T he management of children with complex congenital cardiac disease who have an anatomic and/or physiologic single ventricle demands a thorough un-

From the Division of Cardiothoracic Surgery, ${ }^{a}$ Division of Pediatric Cardiology, ${ }^{\mathrm{b}}$ The Pennsylvania State University, University Hospital, Children's Hospital, The Milton S. Hershey Medical Center, Hershey, Pa.

Read at the Seventy-fourth Annual Meeting of The American Association for Thoracic Surgery, New York, N.Y., April 24-27, 1994

Address for reprints: John L. Myers, MD, Pediatric Cardiothoracic Surgery, Children's Hospital of Pittsburgh, Room 4B465, 3705 Fifth Ave., Pittsburgh, PA 15213

Copyright (C) 1995 by Mosby-Year Book, Inc.

$0022-5223 / 95 \$ 3.00+0 \quad \mathbf{1 2 / 6 / 6 2 0 4 1}$ derstanding of the treatment options. More recently, with advances in fetal echocardiography, these controversial issues are now being raised in the prenatal period. Infants with hypoplastic left heart syndrome (HLHS) exemplify this problem. A palliative staged approach, involving the Norwood/Fontan operations or cardiac transplantation, is currently the established therapy for this complex set of heart defects. ${ }^{1-11}$

Our institution has continued to offer a staged palliative approach for the treatment of patients with HLHS and other similar complex cardiac defects, that is, a Norwood operation with a subsequent modified Fontan operation. With the Norwood operation, the short-term goals are (1) to provide unobstructed systemic blood flow through a 
reconstructed neoaortic arch, (2) to control pulmonary blood flow with a modified Blalock-Taussig shunt so that the pulmonary arterial bed will develop normally, and (3) to create an unrestricted communication between the atria via a complete atrial septectomy. The long-term goals are to achieve either a single Fontan operation or a staged intermediate hemi-Fontan operation followed by a complete Fon$\tan$ operation to completely divide the pulmonary and systemic circulations. We report our results of the Norwood/Fontan staged approach to treat neonates with complex congenital heart defects.

\section{Patients and methods}

From April 1987 to October 1993, 60 infants underwent a first-stage palliative Norwood procedure at the Pennsylvania State University Children's Hospital by a single surgeon (J.L.M.). These patients constitute the study group of this report.

Infants were considered candidates for the procedure if echocardiography showed HLHS or similar complex cardiac defects in which aortic arch reconstruction with incorporation of the pulmonary valve for systemic outflow was required.

The technical aspects of the Norwood procedure have been well described, ${ }^{1,10}$ but a few points require emphasis. Surface cooling is allowed to occur in the operating room during the induction of anesthesia and the placement of vascular lines. Room temperature is maintained at $65^{\circ} \mathrm{F}$. Phentolamine mesylate (Regitine, $0.25 \mathrm{mg} / \mathrm{kg}$ ) and methylprednisolone sodium succinate (Solu-Medrol, $30 \mathrm{mg} / \mathrm{kg}$ ) are administered just before the institution of cardiopulmonary bypass. Systemic cooling is achieved over 20 to 30 minutes, with a final perfusate temperature of $12^{\circ} \mathrm{C}$. These interventions result in a core temperature of $15^{\circ}$ to $18^{\circ} \mathrm{C}$ as measured by venous return and nasal and rectal temperatures. Thiopental $(9 \mathrm{mg} / \mathrm{kg})$ is administered 5 minutes before circulatory arrest. Although cold crystalloid cardioplegia (St. Thomas' Hospital solution) was initially used, over the past 5 years only cold blood cardioplegia (Buckberg solution) has been used. After the establishment of circulatory arrest, the atrial septum is completely excised to ensure unrestricted interatrial communication. The aortic arch is reconstructed with a gusset fashioned from cryopreserved pulmonary allograft tissue (CryoLife, Inc., Marietta, Ga.). Coarctation is avoided by resecting all ductal tissue from the aorta and placing the patch at least $1 \mathrm{~cm}$ distal to the origin of the ductus on the descending aorta. Cardiopulmonary bypass is then reestablished, and the distal main pulmonary trunk is closed with a patch of homograft tissue. A systemic-pulmonary artery shunt from the innominate artery to the right or central pulmonary artery is constructed. This shunt is usually a $4.0 \mathrm{~mm}$ polytetrafluoroethylene conduit for infants weighing more than $3.5 \mathrm{~kg}$ and a $3.5 \mathrm{~mm}$ conduit for infants weighing $3.5 \mathrm{~kg}$ or less.

Postoperatively, all infants receive sedation with intravenous fentanyl while they are supported by mechanical ventilation. Inotropic drugs are instituted when ventricu- lar function is deemed inadequate by either physical examination or echocardiography. Systemic and pulmonary vascular resistances are adjusted primarily by manipulation of the mechanical ventilator and inspired oxygen fraction to achieve a balanced systemic-pulmonary blood flow, which usually results in a systemic oxygen saturation of between $75 \%$ and $85 \%$. We have found the addition of inspired carbon dioxide to the ventilation circuit, as described by Jobes and associates, ${ }^{12}$ essential to achieving good lung expansion that prevents atelectasis without producing hypocarbia that could decrease pulmonary vascular resistance (PVR). The avoidance of pulmonary overcirculation results in improved peripheral perfusion, higher diastolic blood pressure (coronary perfusion pressure), and a more stable cardiovascular course. Sodium nitroprusside is used when needed to lower systemic vascular resistance. After extubation and the establishment of oral nutrition, the infants are usually given digoxin, captopril, and a diuretic.

Patients who are doing well clinically are observed until 18 to 24 months of age, when elective catheterization and a modified Fontan operation are performed. If polycythemia and decreasing arterial oxygen saturations occur earlier, then cardiac catheterization and a modified Fontan operation are performed at that time. Since 1990, those patients who have risk factors for the modified Fontan operation, such as very young age, atrioventricular (AV) valve insufficiency, or small pulmonary arteries, are usually subjected to a hemi-Fontan staging operation. In most cases, the modified Fontan operation consists of a total cavopulmonary connection with a lateral atrial tunnel constructed with a baffle of polytetrafluoroethylene and the creation of a $3 \mathrm{~mm}$ fenestration in the baffle. ${ }^{13,14}$ The hemi-Fontan procedure is constructed as a bidirectional Glenn procedure (superior vena cava-pulmonary artery anastomosis) with ligation of the azygos vein and patch closure of the superior vena caval-atrial junction. ${ }^{15}$ $A V$ valve repair and pulmonary artery augmentation are performed when necessary at this time. Postoperatively, the children are extubated, usually within a few hours of the operation, to enhance pulmonary blood flow by the normal negative intrathoracic pressure that occurs during spontaneous ventilation. Bilateral chest tubes remain in place until the children have established a good oral intake of a low-fat diet and chest tube output resolves. The children are given captopril, digoxin, aspirin, and a diuretic, depending on their intravascular volume status. Cutaneous systemic oxygen saturations are usually between $85 \%$ and $92 \%$ in room air, depending on the amount of shunting through the fenestration of the lateral tunnel for the patients with a modified Fontan repair, and between $75 \%$ and $85 \%$ for those with a hemi-Fontan operation. Cardiac catheterization is performed 1 year after the modified Fontan operation and electively before the Fontan procedure is completed in those patients with a hemi-Fontan operation.

Our Pediatric Cardiac Surgery Database (Summit Medical, Inc., Minneapolis, Minn.), hospital medical records, operative reports, echocardiograms, and catheterization reports were reviewed for all patients. Follow-up was complete for all patients and survival probabilities were determined by Kaplan-Meier methods. Student's $t$ test, 


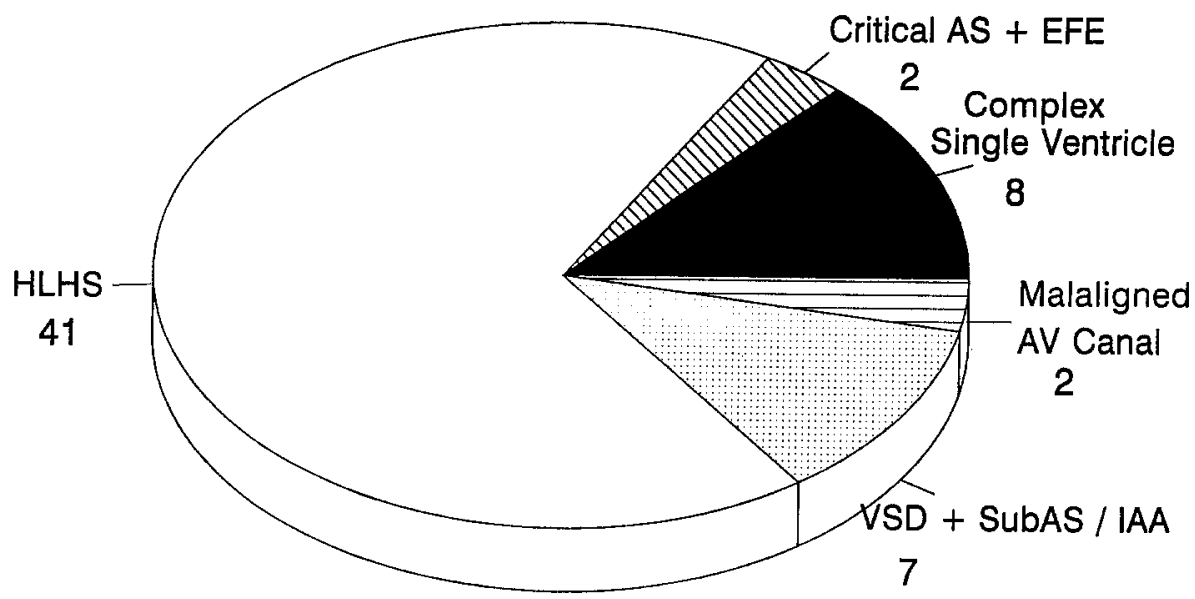

Fig. 1. Morphologic subgroups of the patient population. HLHS, Hypoplastic left heart syndrome; Critical $A S+E F E$, critical aortic stenosis and endocardial fibroelastosis; Malaligned $A V$ Canal, malaligned atrioventricular canal; VSD + SubAS/LAA, ventricular septal defect and subaortic stenosis with or without interrupted aortic arch.

analysis of variance, Cochran-Mantel-Haenszel $\chi^{2}$ test, and Kruskal-Wallis test were used to establish significance between parameters. Univariate and multivariate analyses were used to determine significant risk factors, alone or in combination, that could predict outcome. The following risk factors were evaluated: age, weight, year of operation (1987 to 1989,1990 to 1991,1992 to 1993 ), morphologic subgroups, ascending aortic diameter, circulatory arrest time, and systemic-pulmonary artery shunt size.

\section{Results}

Clinical characteristics. Thirty-nine male infants and 21 female infants underwent the first-stage palliative Norwood operation. The mean age at operation was $9 \pm 18$ days (range 1 to 117 days). The average weight was $3.3 \pm 0.7 \mathrm{~kg}$ (range 1.7 to 5.0 $\mathrm{kg})$. Morphologically, 41 infants (68\%) had HLHS, 7 infants $(12 \%)$ had a ventricular septal defect (VSD) and subaortic stenosis with interrupted aortic arch or severe coarctation, 8 infants $(14 \%)$ had a complex single ventricle, 2 infants $(3 \%)$ had critical aortic stenosis with a small left ventricle and endocardial fibroelastosis, and 2 infants (3\%) had malaligned AV canal defects (Fig. 1). The mean ascending aortic diameter was $4.2 \pm 1.9 \mathrm{~mm}$ (range 1.3 to $9 \mathrm{~mm}$ ) as determined by preoperative echocardiography. In the HLHS group, however, it was only $3.4 \pm 1.4 \mathrm{~mm}$ (range 1.3 to $8 \mathrm{~mm}$ ).

The Norwood operation. The circulatory arrest time averaged $75 \pm 16$ minutes (range 47 to 122 minutes), with a mean total bypass time of $186 \pm 43$ minutes. The mean lowest venous and lowest nasal temperatures achieved during bypass were $16.2^{\circ} \pm$ $1.3^{\circ} \mathrm{C}$ (range $14^{\circ}$ to $19^{\circ} \mathrm{C}$ ) and $17.0^{\circ} \pm 2.0^{\circ} \mathrm{C}$ (range $14.5^{\circ}$ to $26.0^{\circ} \mathrm{C}$ ), respectively. Seven central and 53 modified Blalock-Taussig systemic-pulmonary artery shunts were done. A $4.0 \mathrm{~mm}$ shunt was used in 43 infants, a $3.5 \mathrm{~mm}$ shunt in 11 infants, and a $3.0 \mathrm{~mm}$ shunt in 6 infants.

Total mortality in this series was $50 \%$ (30 of 60 patients). The operative mortality was $33 \%$ ( 20 of 60 patients). The causes of death in these infants included technical problems in two patients, pulmonary failure in six infants (four infants with intact atrial septum before the operation and pulmonary lymphangiectasia), sudden cardiovascular collapse in the intensive care unit in nine infants, shunt occlusion in one patient, and severe AV valve insufficiency in two patients. Six of these 20 infants (30\%) were in poor medical condition before the operation. The operative mortality rate has decreased dramatically with increased experience, as indicated by a $54 \%$ operative mortality (13 of 24 patients) between 1987 and 1989, a 41\% operative mortality ( 7 of 17 patients) between 1990 and 1991, and a $0 \%$ operative mortality ( 0 of 19 patients) between 1992 and 1993 (Table I). A 100\% operative survival (95\% confidence limit: $82.4 \%$ to $100 \%$ ) has been achieved over the past 2 years.

Ten late deaths $(17 \%)$ occurred in this series. Four infants died of respiratory infections. One infant had a sudden cardiovascular collapse at home. Two infants (14 and 16 months of age) had 
Table I. Norwood operation: Results over the years

\begin{tabular}{|c|c|c|c|c|c|c|}
\hline \multirow[b]{2}{*}{ Year } & \multirow[b]{2}{*}{$N$} & \multicolumn{2}{|c|}{$\begin{array}{l}\text { Operative } \\
\text { mortality* }\end{array}$} & \multirow[b]{2}{*}{$95 \%$ CL $(\%)$} & \multicolumn{2}{|c|}{$\begin{array}{c}\text { Late } \\
\text { mortality }+\end{array}$} \\
\hline & & No. & $\%$ & & No. & $\%$ \\
\hline 1986-1989 & 24 & 13 & 54 & $25.6-67.2$ & 3 & 14 \\
\hline $1990-1991$ & 17 & 7 & 41 & $32.9-81.6$ & 4 & 24 \\
\hline $1992-1993$ & 19 & 0 & 0 & $82.4-100$ & 3 & 16 \\
\hline Overall & 60 & 20 & 33 & & 10 & 17 \\
\hline
\end{tabular}

$C L$, Confidence limits.

${ }^{*}$ Decreasing operative mortality, $p<0.0005$.

$\dagger$ Decreasing late mortality, $p=$ not significant.

hypercyanotic episodes and died. In one child, the episode occurred in the evening after a cardiac catheterization was performed for an anticipated Fontan operation, and in the other it occurred during phlebotomy for laboratory tests the evening before a planned Fontan operation. Both had a cardiac arrest and could not be resuscitated. One infant died of severe AV valve regurgitation at 5.4 months, and two infants died of chronic respiratory disease. The average postoperative length of stay for the survivors was $31.6 \pm 22.2$ days (range 12 to 102 days).

Risk analysis. Of the variables analyzed as risk factors for death, age at operation and date of operation were significant when a univariate analysis was performed. Infants who did not survive had a mean age of $3.9 \pm 5.4$ days, whereas survivors had a mean age of $12.7 \pm 21.0$ days $(p=0.000)$. When the three time periods were analyzed, the earlier dates of operation were associated with a higher mortality $(p=0.000)$ (Table II).

From a multivariate analysis, the date of operation remained a risk factor for death $(p=0.006)$, as did the ascending aorta size; infants with a smaller aorta had a significantly higher mortality $(p=0.0408)$.

Subsequent operations

Fontan operation. Twenty-two modified Fontan procedures were performed in 21 of the 30 surviving infants $(70 \%)$. The average age at Fontan repair was $18.1 \pm 8.9$ months (range 7.3 to 46.7 months). All children underwent preoperative catheterization, which revealed a mean systemic oxygen saturation of $77 \% \pm 3 \%$ (range $70 \%$ to $82 \%$ ), a mean PVR of $2.2 \pm 1.0$ Wood units $/ \mathrm{m}^{2}$ (range 0.5 to 5.3 Wood units $/ \mathrm{m}^{2}$ ), a mean pulmonary-systemic flow ratio $(\mathrm{Qp} / \mathrm{Qs}$ ) of $1.1 \pm 0.4$ (range 0.5 to 1.8 ), and a mean McGoon ratio and Nakata index of $1.7 \pm 0.3$ (range 1.3 to 2.4 ) and $275.1 \pm 88.9 \mathrm{~m}^{2} / \mathrm{m}^{2}$ (range 123 to 376 $\mathrm{mm}^{2} / \mathrm{m}^{2}$ ), respectively (Table III).
Table II. Univariate analysis of Nonwood operation

\begin{tabular}{lccc}
\hline & Alive & $\begin{array}{c}\text { Operative } \\
\text { mortality }\end{array}$ & $\begin{array}{c}p \\
\text { Value }\end{array}$ \\
\hline Age (days) & $12.7 \pm 21.0$ & $3.9 \pm 5.4$ & 0.0001 \\
$\begin{array}{l}\text { Surgery date } \\
\quad \text { Earlier surgery: Higher } \\
\quad \text { mortality }\end{array}$ & & & 0.0001 \\
$\begin{array}{l}\text { Circulatory arrest time } \\
\text { Ascending aorta size }\end{array}$ & $72.9 \pm 15.5$ & $79.9 \pm 16.5$ & 0.0577 \\
$\begin{array}{l}\text { Shunt size } \\
\quad \text { Hypothesis: Large shunt } \\
\quad \text { better }\end{array}$ & $4.5 \pm 2.0$ & $3.6 \pm 1.6$ & 0.095 \\
\begin{tabular}{l} 
Weight \\
\hline
\end{tabular} & $3.4 \pm 0.6$ & $3.2 \pm 0.7$ & 0.1359 \\
\hline
\end{tabular}

${ }^{*}$ Cochran-Mantel-Haenszel test for trend of using increasing shunt size over the years, $p=0.046$.

$p$ Value of shunt size, independent of surgery date, is 0.009 .

Table III. Cardiac catheterization data after the Norwood operation

\begin{tabular}{lccc}
\hline & $\begin{array}{c}\text { Before } \\
\text { Fontan } \\
(n=22)\end{array}$ & $\begin{array}{c}\text { Before } \\
\text { hemi-Fontan } \\
(n=5)\end{array}$ & $\begin{array}{c}p \\
\text { Value }\end{array}$ \\
\hline Age (mo) & $18.1 \pm 8.9$ & $8.8 \pm 1.2$ & 0.005 \\
Weight $(\mathrm{kg})$ & $9.4 \pm 2.3$ & $6.7 \pm 0.9$ & 0.004 \\
$\mathrm{SaO}_{2}(\%)$ & $77 \pm 3$ & $78 \pm 2$ & $\mathrm{NS}$ \\
$\mathrm{PVR}\left(\right.$ Wood units $\left./ \mathrm{m}^{2}\right)$ & $2.2 \pm 1.0$ & $2.6 \pm 1.3$ & $\mathrm{NS}$ \\
$\mathrm{Qp} / \mathrm{Qs}$ & $1.1 \pm 0.4$ & $1.4 \pm 0.4$ & 0.046 \\
McGoon ratio & $1.7 \pm 0.3$ & $1.6 \pm 0.2$ & $\mathrm{NS}$ \\
Nakata index & $275 \pm 89$ & $210 \pm 57$ & $\mathrm{NS}$ \\
\hline
\end{tabular}

$\mathrm{SaO}_{2}$, Arterial oxygen saturation; $P V R$, pulmonary vascular resistance; $Q p / Q s$, pulmonary-systemic flow ratio; $N S$, not significant.

Mean cardiopulmonary bypass time was $182 \pm 39$ minutes (range 100 to 245 minutes), with a mean aortic crossclamp time of $84 \pm 41$ minutes (range 4 to 157 minutes). In 18 of the 22 operations, a fenestration was created in the lateral atrial baffle. A $3.0 \mathrm{~mm}$ fenestration was made in ten infants, a 4.0 $\mathrm{mm}$ fenestration in six, and a $5.0 \mathrm{~mm}$ fenestration in one. No early or late mortality has resulted from the modified Fontan operation.

Hemi-Fontan operation. Six infants who were believed to be at higher risk for a Fontan operation entered a three-stage palliative repair schedule by undergoing an intermediate hemi-Fontan operation. The average age at operation was $8.8 \pm 1.2$ months (range 6.8 to 10.4 months). The oldest child was actually 23 months old, but he required conversion from a Fontan to a hemi-Fontan procedure after medically refractory protein-losing enteropathy developed as a result of complete occlusion of the distal left pulmonary artery. An attempt was made to reconstruct the left pulmonary artery at the 
time of the hemi-Fontan operation. Postoperatively, the left pulmonary artery remained stenotic and was balloon dilated. It ultimately was stented with a Palmaz iliac stent (Johnson \& Johnson Cardiovascular, King of Prussia, Pa.). Subsequently, reoperation has returned his repair to a fenestrated full Fontan with an excellent result including no recurrence of protein-losing enteropathy.

Children who had a hemi-Fontan procedure underwent preoperative catheterization, which revealed a mean systemic saturation of $78 \% \pm 2 \%$ (range $75 \%$ to $81 \%$ ), a PVR of $2.6 \pm 1.3$ Wood units (range 1.1 to 5.3 Wood units), a mean Qp/Qs of $1.4 \pm 0.4$ (range 1.1 to 2.2), and mean McGoon ratio and Nakata index of $1.6 \pm 0.2$ (range 1.3 to 1.9 ) and $210 \pm 57$ (range 139 to $279 \mathrm{~mm}^{2} / \mathrm{m}^{2}$ ), respectively (see Table III). No deaths (early or late) have occurred in these six patients, and currently two patients have successfully completed their final palliation by undergoing the third-stage completion Fontan operation at 46.7 and 23.0 months of age.

Two-ventricle repair (Rastelli operation). Two children (one with VSD, severe subaortic stenosis, and interrupted aortic arch and one with double-outlet right ventricle, VSD, and aortic atresia) were able to undergo a two-ventricle repair by having a Rastelli operation at 7.4 and 14.1 months of age. No early or late deaths occurred.

Interventional procedures. Interventional cardiac catheterization was performed in five patients. This included two balloon angioplasties for left pulmonary artery stenosis after the modified Fontan operation. Both patients eventually required endovascular stenting. One patient had transseptal puncture followed by balloon angioplasty of a spontaneously closed fenestration that was associated with significant, recalcitrant pleural effusions. One patient had successful balloon angioplasty of a distal neoaortic arch coarctation. One patient had closure of a fenestration with a clamshell device because of excessive right-to-left shunting and clinically important hypoxemia.

Late follow-up. Mean follow-up for the 30 survivors of the Norwood operation was $29.2 \pm 20.4$ months (range 3.1 to 78.7 months). The average oxygen saturation during clinic visits of the patients with a modified Fontan operation was $90 \% \pm 4 \%$ (range $81 \%$ to $96 \%$ ). Their mean percentile weight was $29 \% \pm 23 \%$ (range $5 \%$ to $75 \%$ ). Fifty-seven percent were receiving diuretics, $57 \%$ afterload reducing agents, and $80 \%$ digoxin. Echocardiograms after the Fontan operation $(n=22)$ revealed neo- aortic valve insufficiency (trace in seven infants, mild in six, moderate in one) and AV valve insufficiency (none or trace in nine patients, mild in eight, moderate in three, and severe in one). The fenestration was noted to have spontaneously closed in four of 18 patients (all with $3.0 \mathrm{~mm}$ fenestrations) who had a fenestrated lateral atrial baffle. Ventricular function was good in 17 patients and was decreased in four patients.

Catheterization after the Fontan operation has been performed in 11 patients (mean age 3.5 years). Aortic saturations were $92 \% \pm 3 \%$, PVR was $1.4 \pm$ 0.5 Wood units $/ \mathrm{m}^{2}$, and the Qp/Qs ratios were $1.0 \pm$ 0.3 (range 0.7 to 2.0 ). The patient who had the Qp/Qs of 2.0 had numerous small aortopulmonary collaterals that were not amenable to coil embolization.

Kaplan-Meier survival curves for the three aforementioned periods have been generated (Fig. 2) and reveal an $85 \%$ overall survival for patients having undergone the original Norwood operation between 1992 and 1993, a 33\% overall survival for those patients operated on between 1987 and 1989, and a $35 \%$ survival for those operated on between 1990 and 1991.

\section{Discussion}

Not long ago, the prognosis for infants born with HLHS was considered uniformly fatal, because $95 \%$ did not survive the first month of life. ${ }^{16}$ HLHS was the most common cause of death due to heart disease in the newborn period. ${ }^{16}$ As a result of pioneering efforts over the past decade by Norwood and colleagues ${ }^{9,10,14}$ in the area of palliative surgery and Bailey, ${ }^{7}$ Backer, ${ }^{8}$ and their associates in the area of cardiac transplantation, the outlook for these infants has dramatically improved.

In centers offering first-stage palliative Norwood operations as the primary mode of therapy for HLHS, the general trend has been toward improved survival stemming from continued experience with both the operation and postoperative management. ${ }^{1,3}$ At the symposium on hypoplastic left heart syndrome in $1985,{ }^{17}$ there was a combined $70 \%$ (174 of 249 patients) operative mortality rate. However, the centers treating fewer than 16 patients had a 91\% (101 of 111 patients) mortality rate, compared with a $53 \%$ ( 73 of 138 patients) rate for centers that treated more than 35 patients. Recently, Iannettoni and colleagues ${ }^{1}$ reported on their improved operative mortality rate-from $58 \%$ (29 of 50 patients) between 1986 and 1989 to $15 \%$ (11 of 73 patients) over 


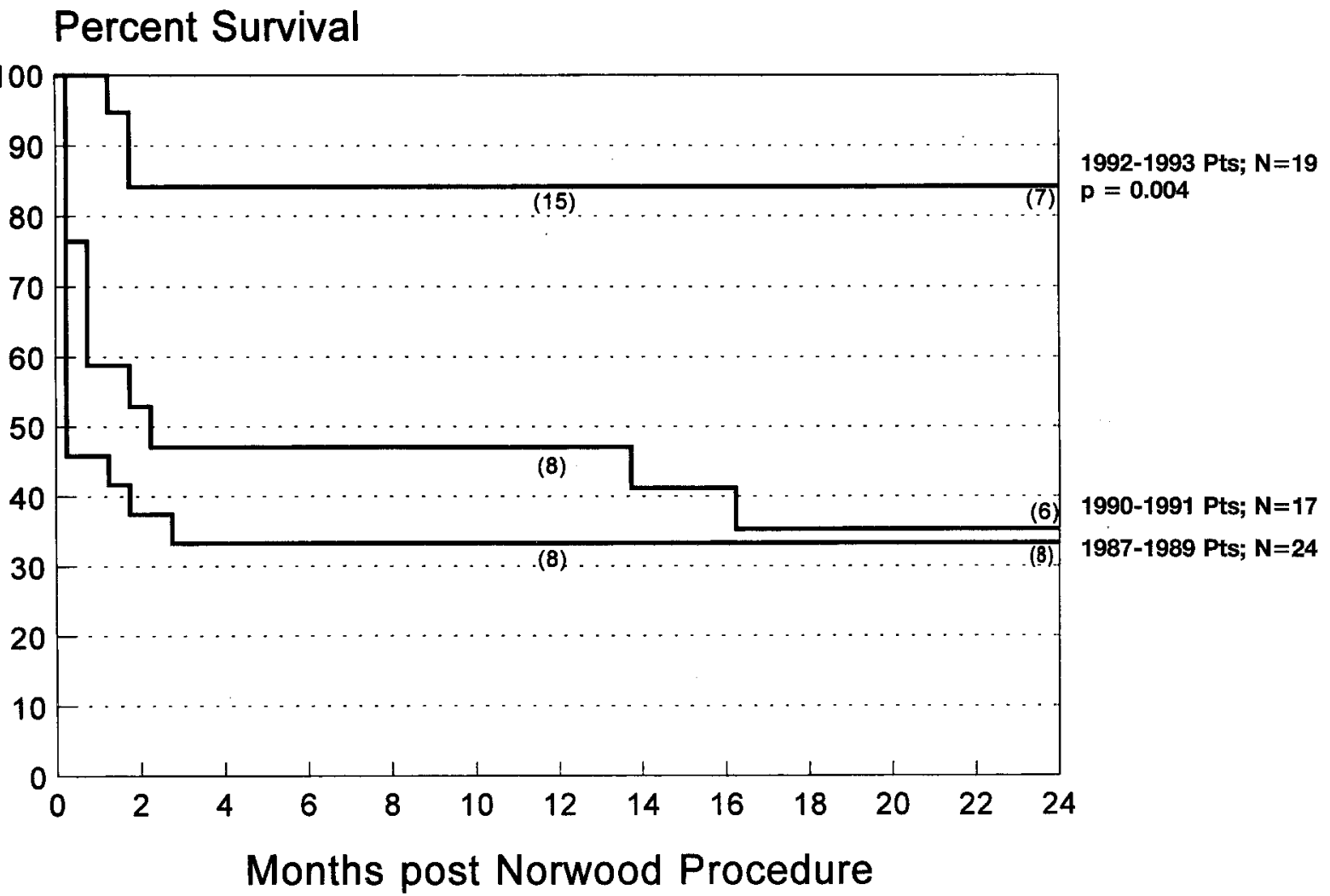

Fig. 2. Kaplan-Meier survival analysis of the Norwood/Fontan staged palliation. Percent survival calculated after the Norwood procedure. The numbers in parentheses indicate the number of patients alive at 12 and 24 months. The standard error of the estimate for the three time periods $(1987-1989,1990-1991$, and $1992-1993$ ) is $9.62,12.11$, and 9.35 , respectively.

the past 3 years. Our results have also improved from a $54 \%$ operative mortality rate between 1986 and 1989 to a $0 \%$ mortality rate between 1992 and 1993.

The balance of pulmonary and systemic blood flow after the Norwood operation would appear to be centrally related to these improved results. This importance is reflected by the nine (of the 20) operative deaths $(45 \%)$ in our series that were due to sudden cardiovascular collapse in the intensive care unit. First, high circulating levels of endogenous catecholamines are known to exist after cardiopulmonary bypass, especially with hypothermic circulatory arrest. ${ }^{18}$ Sedation with continuous intravenous fentanyl may play a key role in avoiding sudden increases in systemic and pulmonary vascular resistance that can occur with suctioning or chest physiotherapy. Pigott and coworkers ${ }^{10}$ noted in their series that early postoperative mortality was most commonly associated with alterations in ventilation and often accompanied endotracheal suctioning. Acute decreases in PVR that result from hyperven- tilation lead to low diastolic blood pressure (decreased coronary perfusion) and, in conjunction with an increased volume load on the ventricle from pulmonary overcirculation, create a situation for myocardial ischemia and circulatory collapse. Sudden increases in PVR can cause a significant reduction of pulmonary blood flow, resulting in severe hypoxemia that can lead to cardiac ischemia. A more stable cardiovascular course has been achieved by the addition of inspired carbon dioxide to the ventilation circuit, as described by Jobes and associates. ${ }^{12}$ Since its incorporation into our postoperative routine in the past 2 years, there have been no operative deaths. The ideal postoperative mechanical ventilation results in a carbon dioxide tension of between 35 and 45 torr, an arterial oxygen tension of between 35 and 45 torr, and a $\mathrm{pH}$ of between 7.35 and 7.45. Postoperatively, the lungs are more susceptible to the development of atelectasis caused by airway edema and bronchial secretions; therefore, generous tidal volumes and positive end-expiratory 


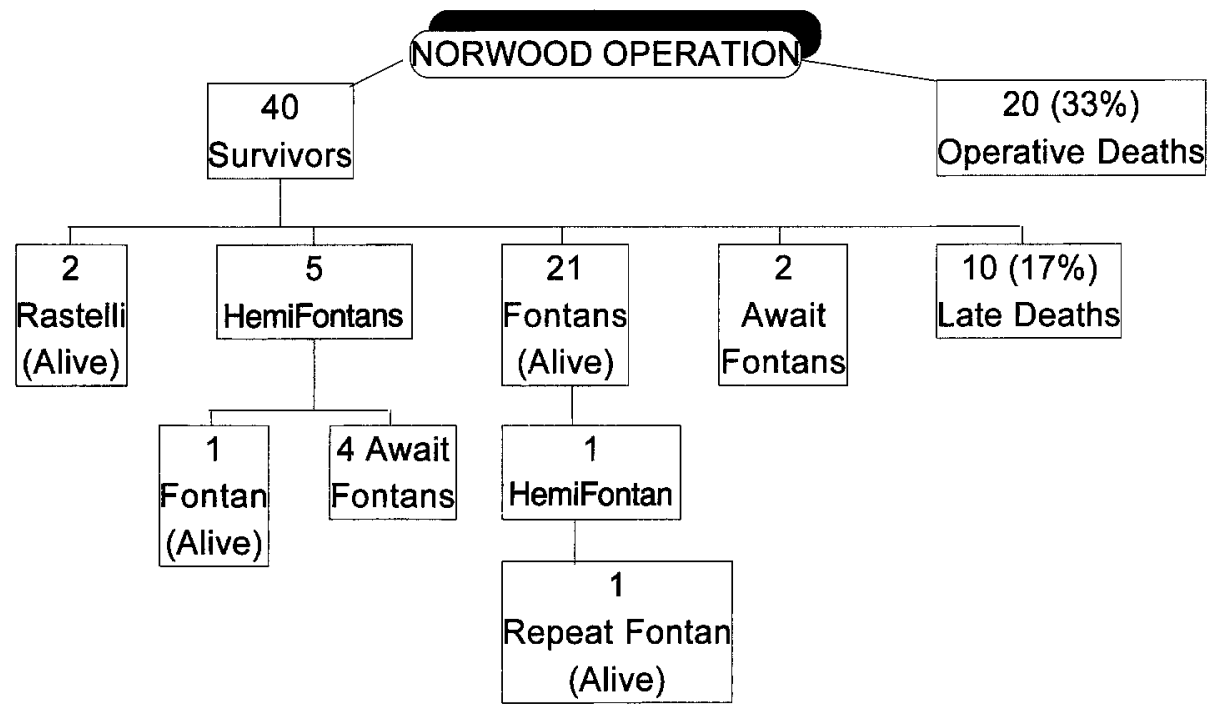

Fig. 3. Fate of patients undergoing Norwood operation.

pressure ( 2 to $5 \mathrm{~cm} \mathrm{H}_{2} \mathrm{O}$ ) are needed to help prevent atelectasis. This mode of ventilation ordinarily results in some degree of overventilation and hypocarbia. For the desired carbon dioxide tension to be maintained with mechanical ventilation alone, tidal volume and rate must be decreased. The result frequently is atelectasis. Atelectasis and alveolar hypoxemia are potent stimulants for pulmonary vasoconstriction. In combination with the already high levels of circulating catecholamines, atelectasis and alveolar hypoxemia may prompt sudden elevations in PVR that can abruptly reduce pulmonary blood flow and give rise to serious hypoxemia. The use of inspired carbon dioxide allows one to ventilate the patient's lungs with good tidal volumes and to use positive end-expiratory pressure to promote lung expansion and prevent atelectasis, while at the same time maintaining the arterial carbon dioxide at the desired level.

Analysis of perioperative variables to identify risk factors associated with the Norwood operation revealed that the earlier time in which the operation was performed and younger age at operation were both risk factors for operative mortality. As noted earlier, survival has improved substantially over the three time periods evaluated. Although the circulatory arrest time between survivors and nonsurvivors did not differ significantly ( $72.9 \pm 15.5$ versus $79 \pm$ 16.5 minutes), there was a significant decrease in arrest time over the three study periods. The mean circulatory arrest time was $87.7 \pm 18.3$ minutes between 1987 and 1989, 75.0 \pm 11 minutes between
1990 and 1991, and $63.4 \pm 6$ minutes between 1992 and 1993 ( $p<0.005$, analysis of variance).

It is of interest that the nonsurvivors were significantly younger than the survivors (3.8 days for nonsurvivors versus 12.5 days for the survivors, $p<0.05$ ), since Iannettoni and coworkers ${ }^{1}$ noted a higher mortality in children who were operated on after 1 month of age. This discrepancy does not necessarily conflict with their conclusions. There is a trend in our series over the three time periods of operating on slightly older infants ( 15 days between 1992 and 1993 versus 6.3 days for 1987 through 1989 and 7.9 days for 1991 to 1992; no significant difference). This trend may be due to the fact that with more experience with preoperative resuscitation and management, there has been more willingness to allow the condition of these infants to stabilize before the Norwood operation.

Patients undergoing the second-stage Fontan or hemi-Fontan procedure in this series have had excellent results, with $100 \%$ survival with either operation, both early and late. These results are consistent with other series and lend support to the concept of a multistage approach to these congenital defects (Fig. 3).

In our institution, 42 patients under 2 years of age have undergone a modified Fontan operation with only one operative mortality. Because of our previous excellent results with a two-stage approach, we have elected to use the hemi-Fontan operation on a selective basis for those patients who are believed to be at higher risk for a modified Fontan operation. This procedure was performed at an age of $8.8 \pm 1.2$ 
months in our series, versus an age of $18.1 \pm 8.9$ months for the modified Fontan operation. The hemi-Fontan operation does reduce the volume load on the single ventricle, thereby preventing further hypertrophy that may increase the risk at the modified Fontan operation. It also allows earlier repair of branch pulmonary artery stenosis or AV valve incompetence, which may further improve the patient's risk for a modified Fontan operation. All of our hemi-Fontan operations included augmentation of the branch pulmonary arteries, and three of the six included repair of AV valvular insufficiency. Four of the six patients are currently awaiting completion Fontan operations.

Results in two patients who underwent a twoventricle repair by a Rastelli operation also support the concept that the Norwood operation is a reasonable procedure to stabilize the condition of an infant with two good ventricles and a VSD, but with significant left ventricular outflow tract obstruction before eventual two-ventricle repair.

Interestingly, the only spontaneous closure of fenestrations occurred in patients with a $3.0 \mathrm{~mm}$ diameter fenestration (4 of 18 patients) and may indicate a threshold size for spontaneous closure. Cardiac catheterizations after the Fontan operation revealed good hemodynamics and showed that the PVR decreased from pre-Fontan levels $(2.2 \pm 1.0$ to $1.4 \pm 0.5$ Wood units).

The improved Kaplan-Meier survival of $85 \%$ for those patients operated on between 1992 and 1993 is up from $33 \%$, and $35 \%$ for those patients treated during the two earlier periods. Longer follow-up is necessary to determine the ultimate fate of these children undergoing multiple cardiac operations terminating in a modified Fontan operation.

In summary, the Norwood operation has become a realistic procedure to offer infants with certain complex congenital heart defects. Acceptable results have now been achieved at a number of institutions. A multistaged approach does not necessarily impart any increased risk over a one-stage cardiac transplant approach.

We thank Cindy Miller for the statistical analysis and graphs and Michelle Lauzon for the preparation of this paper.

\section{REFERENCES}

1. Iannettoni MD, Bove EL, Mosca RS, et al. Improving results with first-stage palliation for hypoplastic left heart syndrome. J Thorac Cardiovasc Surg 1994; 107:934-40.

2. Jonas RA. Intermediate procedures after first-stage Norwood operation facilitate subsequent repair. Ann Thorac Surg 1991;52:696-700.

3. Norwood WI. Hypoplastic left heart syndrome. Ann Thorac Surg 1991;52:688-95.

4. Murdison KA, Baffa JM, Farrell PE, et al. Hypoplastic left heart syndrome: outcome after initial reconstruction and before modified Fontan procedure. Circulation 1990;82(Suppl):IV199-207.

5. Meliones JN, Snider AR, Bove EL, Rosenthal A, Rosen DA. Longitudinal results after first-stage palliation for hypoplastic left heart syndrome. Circulation 1990;82(Suppl):IV151-6.

6. Jonas RA, Lang P, Hansen D, Hickey P, Castaneda AR. First-stage palliation for hypoplastic left heart syndrome. J Thorac Cardiovasc Surg 1986;92:6-13.

7. Bailey LL, Assaad AN, Trimm RF, Nehlsen-Cannarella SL, Kanakriyeh MS, Haas GS. Orthotopic transplantation during early infancy as therapy for incurable congenital heart disease. Ann Thorac Surg 1988;208: 279-86.

8. Backer CL, Zales VR, Harrison HL, Idriss FS, Benson DW Jr, Mavroudis C. Intermediate-term results of infant orthotopic cardiac transplantation from two centers. J Thorac Cardiovasc Surg 1991;101:826-32.

9. Norwood WI, Kirklin JK, Sanders SP. Hypoplastic left heart syndrome: experience with palliative surgery. Am J Cardiol 1980;45:87-91.

10. Pigott JD, Murphy JD, Barber G, Norwood WI. Palliative reconstructive surgery for hypoplastic left heart syndrome. Ann Thorac Surg 1988;45:122-8.

11. Norwood WI Jr, Jacobs ML, Murphy JD. Fontan procedure for hypoplastic left heart syndrome. Ann Thorac Surg 1992;54:1025-30.

12. Jobes DR, Nicolson SC, Steven JM, Miller M, Jacobs ML, Norwood WI Jr. Carbon dioxide prevents pulmonary overcirculation in hypoplastic left heart syndrome. Ann Thorac Surg 1992;54:150-1.

13. Jonas RA, Castaneda AR. Modified Fontan procedure: atrial baffle and systemic venous-to-pulmonary artery anastomotic techniques. J Cardiac Surg 1988; 3:91-6.

14. de Leval MR, Kilner P, Gewillig M, Bull C. Total cavopulmonary connection: a logical alternative to atriopulmonary connection for complex Fontan operations. J Thorac Cardiovasc Surg 1988;96:682-95.

15. Douville EC, Sade RM, Fyfe DA. Hemi-Fontan operation in surgery for single ventricle: a preliminary report. Ann Thorac Surg 1991;51:893-900.

16. Fyler DC. Report of the New England Regional Infant Cardiac Program. Pediatrics 1980;65(Suppl):463.

17. Sade RM. Symposium on hypoplastic left heart syndrome [Letter]. J THORAC CARDIOVASC SURG 1986;91: 937-9. 
18. Anand KJS, Hickey PR. Halothane-morphine compared with high-dose sufentanil for anesthesia and postoperative analgesia in neonatal cardiac surgery. $\mathrm{N}$ Engl J Med 1992;326:1.

\section{Discussion}

Dr. Richard A. Jonas (Boston, Mass.). I would like to begin by congratulating the authors on these outstanding results. I agree that reconstructive surgery for this complex spectrum of malformations is an excellent measure of institutional expertise rather than being a simple measure of personal surgical skills.

We recently published an analysis of our experience with HLHS in which we found that preoperative insult, determined by the worst $\mathrm{pH}$ experienced before the operation, was the most powerful determinant of both early and late outcome. We also found that the diameter of the ascending aorta tended to influence outcome: patients who had a particularly small ascending aorta, less than $2 \mathrm{~mm}$ in diameter, tended to do worse. We also found, by looking at morphologic subgroups, that patients with aortic atresia and mitral stenosis tended to have a higher early mortality and patients with aortic atresia and mitral atresia had a worse late outcome.

I have two questions. Although you did not analyze preoperative insult as a patient-related predictor of outcome, was it your impression that this influenced mortality and is it possible that a higher rate of prenatal diagnosis and consequent improved preoperative status may have contributed to your improving results? Second, after the introduction of the bidirectional shunt we have felt comfortable placing smaller shunts at the first stage, whereas you stated that you have used larger shunts with time. Do you believe that this has contributed to greater patient stability? Certainly our impression has been that smaller shunts have contributed to greater patient stability, and perhaps this is the reason we have not felt the need to use carbon dioxide.
Are you seeing more patients in whom the diagnosis has been made prenatally? Do you think that the overall status of patients is improving with time?

Dr. Joseph J. Amato (New Hyde Park, N.Y.). I rise on a point of clarity. You showed a slide on the analysis of your Norwood operation and pointed out circulatory arrest times in patients who are alive to be $72.9 \pm 15.5$ minutes, as compared with $79.9 \pm 16.5$ minutes for those who died (operative mortality). It was not clear whether you were referring to crossclamp time, bypass time, or arrest time? I find that in the conduction of the Norwood operation this circulatory arrest time is really necessary in this group of patients. In an earlier paper at this meeting, presented by the Boston Children's Hospital, there was a definite increase in neurologic abnormalities because of extended arrest times that were longer than the "safe period." Our personal experience with this lesion shows that longer circulatory arrest times are necessary in these patients, and I question whether there should be some reevaluation of the safe period for it.

Dr. Weldner. I would agree, Dr. Jonas, that those patients with a significant preoperative insult are more likely to be sick postoperatively; however, several patients who had a "worst $\mathrm{pH}$ " less than 7.0 have surprisingly done extremely well. I do think we are seeing more patients in whom the diagnosis was made prenatally and these patients should be in much better shape preoperatively. The $4 \mathrm{~mm}$ shunt does result in more pulmonary blood flow and the potential for excessive pulmonary overcirculation. On the other hand, hypoxemia is rarely a problem and the use of inspired carbon dioxide has controlled pulmonary blood flow. We do use a $3.5 \mathrm{~mm}$ shunt in patients less than 3.0 to $3.5 \mathrm{~kg}$.

Dr. Amato, the mean circulatory arrest time that we report is the total circulatory arrest time, which is also the cardiac ischemic time (crossclamp time). I believe that long-term follow-up of these patients particularly from a neurodevelopment viewpoint will add important information regarding the "safe period" for deep hypothermia and total circulatory arrest. 